Discussion Paper No. 04-20

\title{
Discrete Working Time Choice in an Applied General Equilibrium Model
}

Stefan Boeters, Michael Feil and Nicole Gürtzgen

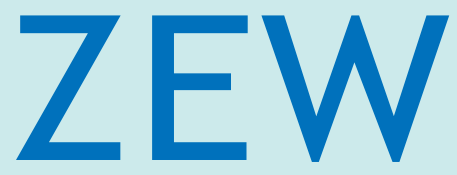

Zentrum für Europäische Wirtschaftsforschung $\mathrm{GmbH}$

Centre for European

Economic Research 
Discussion Paper No. 04-20

\title{
Discrete Working Time Choice in an Applied General Equilibrium Model
}

\author{
Stefan Boeters, Michael Feil and Nicole Gürtzgen
}

Download this ZEW Discussion Paper from our ftp server:

\author{
ftp://ftp.zew.de/pub/zew-docs/dp/dp0420.pdf
}

Die Discussion Papers dienen einer möglichst schnellen Verbreitung von neueren Forschungsarbeiten des ZEW. Die Beiträge liegen in alleiniger Verantwortung der Autoren und stellen nicht notwendigerweise die Meinung des ZEW dar.

Discussion Papers are intended to make results of ZEW research promptly available to other economists in order to encourage discussion and suggestions for revisions. The authors are solely responsible for the contents which do not necessarily represent the opinion of the ZEW. 


\section{Non-technical summary}

We present a model that integrates the discrete working time choice of heterogenous households into a general equilibrium setting where wages are determined by sectoral bargaining between firms and trade unions. The model integrates microeconomic work based on microsimulation models and macroeconomic experiences with representative agent models. Basically, it is an applied general equilibrium (AGE) model with 26 different household types. Each of them represents a different socioeconomic group. Each person has to decide on the amount of labour supplied to the market. (S)he can choose from a small number of working time options, among them non-participation. The net income associated with each working time option is endogenously determined and depends on flexible producer wages as well as taxes and transfers. This labour supply module is combined with a bargaining setup for wage determination and embedded in a standard AGE model in the tradition of Shoven and Whalley (1984).

The model is calibrated to German micro and macro data. We then use it to analyse stylised policy reforms that are designed to stimulate labour supply. In the first scenario, the basic social assistance (SA) rate ("Regelsatz") is cut by 50 per cent for all household members (adults and children). In the second scenario, individuals with large child care responsibilities, i.e. single parents with more than one child and women in couple households with more than one child, are exempted from the SA rate cut. In both cases, we report macroeconomic changes as well as effects on the participation rate, average working hours and labour supply for different subsets of households. 


\title{
Discrete Working Time Choice
}

\section{in an Applied General Equilibrium Model}

\author{
Stefan Boeters ${ }^{* \dagger}$, Michael Feil**, Nicole Gürtzgen* \\ *Centre for European Economic Research, Mannheim \\ **Institute for Employment Research (IAB), Nürnberg
}

February 2004

\begin{abstract}
We present a model that integrates the discrete working time choice of heterogenous households into a general equilibrium setting where wages are determined by sectoral bargaining between firms and trade unions. The model is calibrated to German micro and macro data. We then use it to analyse stylised policy reforms that are designed to stimulate labour supply.
\end{abstract}

Keywords: applied general equilibrium, discrete working time choice, labour market, trade unions, wage bargaining, labour market reform

JEL Code: D58, J22, J51

\footnotetext{
${ }^{\dagger}$ Corresponding author: Stefan Boeters, Centre for European Economic Research, PO Box 103443, D-68034 Mannheim, e-mail: boeters@zew.de. We thank Peter Jacobebbinghaus for furnishing us with the necessary output from the ZEW's microsimulation model, Reinhold Schnabel for stimulating discussion and Ed Westerhout, Gerd Zika, Bettina Müller and François Laisney for helpful comments on earlier versions of this paper.
} 


\section{Introduction}

The tax and benefit system ranks prominently among the factors that are presented to explain the high levels of unemployment in many European countries. One important problem is recognised with work disincentives at the lower end of the earnings distribution. There are mainly two reasons why the transfer paid to every citizen who is not able to earn their living on their own often works as a barrier to employment. First, benefit payments are high compared to the incomes that low skilled workers can earn in the labour market, and second, benefit withdrawal rates are often close to 100 per cent, i.e. additional income earned leads to a one-to-one reduction in benefit payments. Together these two elements create "poverty traps", which keep benefit recipients within the welfare system instead of promoting their transition into employment. This problem has been highlighted both in academics and politics, and has given rise to a variety of reform proposals: a reduction in social assistance rates, a reduction in the replacement rate or the duration of unemployment insurance payments, several variants of a negative income tax, an income allowance for social security contributions, or the promotion of special "mini" or "midi" jobs in the low income sector.

The most prominent reform proposals in Germany are studies of the Scientific Advisory Board to the German Federal Ministry of Economics (Bundesministerium für Wirtschaft, 2002), of the Munich based ifo institute (Sinn et al., 2002) and of the German Council of Economic Experts (2002). They suggest a significant simultaneous reduction in social assistance payments and in benefit withdrawal rates. The assessment of policy proposals must take into account direct labour supply effects and indirect wage and labour demand effects. A suitable analytical approach must thus contain both "micro" parts (the individual decisions in heterogeneous 
households) and "macro" parts (market interactions in the whole economy).

At the micro level of labour supply, recent econometric work has focused on the simultaneous analysis of participation and hours of work decisions under nonconvex budget constraints (see Blundell and MacCurdy, 1999, for a survey). This question has usually been approached in model settings where households choose between a fixed number of labour supply options, among them non-participation. Reaction coefficients are then estimated by discrete choice methods, whereas incomes for alternative labour market options are treated as exogenous parameters.

By combining a discrete-choice labour supply model with a net income calculator, one arrives at behavioural microsimulation models that can be used to assess the reform effects in the tax and transfer system at given wages. The strength of microsimulation models is the very detailed modelling of the individual households' budget constraints. They can thus account for the fact that the decisions of partners in couple households also depend upon the labour market status and options of the spouse. However, microsimulation models are typically not closed, i.e. there is no mechanism to assure a macroeconomic equilibrium.

In contrast, macroeconomic work has focused on price and wage changes and their impact on labour demand. Labour supply is often treated in a very rough way in macroeconomic studies. It is either accommodated by the assumption of a representative household or even treated as completely exogenous. This means that labour supply is neither differentiated between persons and hours nor between different households.

The model we describe in this paper is an attempt to integrate microsimulation models with heterogeneous households and macrosimulation models. The model ist able to (1) cover the main features of reforms in the tax and transfer system, (2) 
describe the behavioural reaction on the micro level, and (3) determine the general equilibrium effects on wages and employment. To this end, we construct an applied general equilibrium model (AGE) with 26 different households, each representing a different socioeconomic group. Each person has to decide on the amount of labour supplied to the market and chooses from a small number of working time options, among them non-participation. The net income associated with each working time option is endogenously determined and depends on flexible producer wages as well as taxes and transfers. This labour supply module is combined with a bargaining setup for wage determination and embedded in a standard AGE model in the tradition of Shoven and Whalley (1984). The AGE approach provides a comprehensive and consistent framework of production and consumption interactions in the economy and has become the standard tool for the analysis of the economy-wide impacts of policy measures on resource allocation and the associated implications for incomes of economic agents (for surveys on the use of AGE models in different policy fields, see Shoven and Whalley, 1992, Pereira and Shoven, 1992, Kehoe and Kehoe, 1994, or Weyant, 1999).

The model in this paper extends former work (Böhringer, Boeters, and Feil, 2002) by using the AGE model PACE-L as its basis. The Dutch MIMIC model (Graafland et al., 2001) provides us with a central idea which we use in setting up the households' utility functions. We also utilise the ZEW's microsimulation model (Jacobebbinghaus and Steiner, 2003), which consists of a net income calculator and a logit labour supply estimation based on van Soest (1995). The model is 'micro', because the household submodel is built on individual data and calibrated to results from a discrete choice model. It is 'macro', because it uses the representative agent assumption and is closed.

Micro-macro modelling strategies have become increasingly popular over the last 
decade (see e.g. Dixon, Malakelis, and Meagher, 1996, or Baekgaard and Robinson, 1997). In most cases, they are motivated by distributional concerns, in particular in development economics (for a survey see Davies, 2003). In general, integrating micro-information requires a vast increase in the number of economic agents. This can be done either sequentially or by complete merger of AGE and microsimulation models (as, e.g., in Cogneau and Robilliard, 2000, or Bourguignon, Robilliard, and Robinson, 2003).

In Davies's terms, our approach falls into the plain "AGE" class, but cannot be classified as "AGE microsimulation", because we do not simulate the behaviour of each individual household in the original data set. Nevertheless, the use of microsimulation data to calibrate the AGE model is an important part of our modelling approach. Together with the MIMIC model it is the only attempt to combine heterogeneous, discrete labour supply and an economy-wide model with full endogeneity of all major economic variables.

The remainder of the paper is organised as follows: In Sections 2 and 3, we describe in detail the core labour supply elements of the model and their calibration to the output of a microsimulation model. Section 4 then gives a brief overview of the general equilibrium model in which the labour supply module is embedded. Section 5 reports the results of some illustrative policy simulations of cuts in the social assistance. In Section 6, we summarise and draw conclusions. An appendix provides additional information about the aggregation structure of the model and the German tax and transfer system. 


\section{A model of discrete working time choice}

The core element of our model is a labour supply module in which we distinguish 26 household types according to household composition and skill of the members, 10 of them single households and 16 couple households. More information is provided in Table 3 in the appendix. Each individual (single or member of a household) can choose from a fixed number of discrete labour supply options. For single males without children and for married males, there are three labour supply options. For all other household types (married women, single females without children and singles with children) there are five options. The discrete options have been chosen so that they correspond to the empirical distribution of labour supply behaviour of the different types of individuals (Buslei and Steiner, 1999). For all individuals the first option is non-participation (zero hours of work). All options are summarised in Table 4 in the appendix.

Each household is characterised by a utility function that consists of two additive parts. The first one is a CES part, which depends on leisure and consumption, as in the standard neoclassical labour supply model. The second part is linear in the absolute difference between actual and desired working time. Through the parameter of desired working time, we generate heterogeneity within household types. Algebraically, the utility for a single household $i$ of type $j$ supplying labour in hours category $k$ is calculated as

$$
U_{i, j}\left(h_{j, k}\right)=\left[\alpha_{j}^{L}\left(T-h_{j, k}\right)^{\frac{\sigma_{j}-1}{\sigma_{j}}}+\left(1-\alpha_{j}^{L}\right) C_{j}\left(h_{j, k}\right)^{\frac{\sigma_{j}-1}{\sigma_{j}}}\right]^{\frac{\sigma_{j}}{\sigma_{j}-1}}-\beta_{j}\left(\left|h_{j, k}-\bar{h}_{j, i}\right|\right),
$$

where $\alpha_{j}^{L}$ : share parameter of leisure, $T$ : time endowment, $h_{j, k}$ : working time in hours category $k, C_{j}$ : average consumption, $\sigma_{j}$ : elasticity of substitution within the CES part, $\beta_{j}$ : weighting parameter for the disutility that results when actual 
working time deviates from desired working time, $\bar{h}_{j, i}$. The actual working hours differ within household types due to the heterogeity of $\bar{h}_{j, i}$. This way of modelling household heterogeneity simplifies the calibration to empirical elasticities. A similar approach can be found in Graafland et al. (2001, pp. 71-86).

Couples' labour supply choice is derived from a joint utility function that depends on the hours combinations $\left(h_{j, k}^{f}, h_{j, l}^{m}\right)$, where the individual spouses are indexed by $i$ and $g$ and the superscripts $f$ and $m$ refer to women and men, respectively:

$$
\begin{aligned}
U_{g, i, j}\left(h_{j, k}^{f}, h_{j, l}^{m}\right)=\left[\alpha_{j}^{L}\left(L_{j}\left(h_{j, k}^{f}, h_{j, l}^{m}\right)\right)^{\frac{\sigma_{j}-1}{\sigma_{j}}}\right. & \left.+\left(1-\alpha_{j}^{L}\right)\left(C_{j}\left(h_{j, k}^{f}, h_{j, l}^{m}\right)\right)^{\frac{\sigma_{j}-1}{\sigma_{j}}}\right]^{\frac{\sigma_{j}}{\sigma_{j-1}}} \\
& -\beta_{j}^{f}\left(\left|h_{j, k}^{f}-\bar{h}_{j, i}^{f}\right|\right)-\beta_{j}^{m}\left(\left|h_{j, l}^{m}-\bar{h}_{j, g}^{m}\right|\right) .
\end{aligned}
$$

$L_{j}\left(h_{j, k}^{f}, h_{j, l}^{m}\right)$ denotes joint leisure of the couple and is defined as

$$
L_{j}\left(h_{j, k}^{f}, h_{j, l}^{m}\right)=\left(\alpha_{j}^{f}\left(T-h_{j, k}^{f}\right)+\left(1-\alpha_{j}^{f}\right)\left(T-h_{j, l}^{m}\right)\right)
$$

with $\alpha_{j}^{f}$ representing a weighting parameter for female leisure. $C_{j}\left(h_{j, k}^{f}, h_{j, l}^{m}\right)$ denotes joint consumption which is derived from the total disposable household income. In the following, we explain the basic steps of the determination of the labour supply choice by the simpler case of singles according to (1).

For each individual there are several distinct labour market states, which result from three dichotomies: (1) Each individual can be either voluntarily unemployed (supplying zero hours of work) or participate in the labour market. (2) If it supplies positive hours of work, it is either employed or unvoluntarily unemployed. (3) In the event of unvoluntary unemployment, it is either eligible for unemployment benefits or not. The share of unvoluntary unemployment in all unemployment by household 
type is taken from survey data in the German Socioeconomic Panel (GSOEP), where people are asked whether they actually want to work. This fraction is rescaled, so as to meet empirical aggregate unemployment rates, subtracted from those households supplying zero working hours and is then uniformly added to all other working time categories (resulting in a uniform rate of involuntary unemployment for all positive working time categories). The probabilities of receiving either unemployment benefits or social assistance payments if unemployed are uniformly fixed through aggregate data in the benchmark year.

With these probabilities, we calculate average consumption $C_{j}\left(h_{j, k}\right)$ over the three labour market states (employed, unemployed with or without unemployment benefit entitlement) and for all working time categories $k$, applying the rules of the German tax and transfer system. This average consumption is used as an approximation for the expected utilities. More detail concerning the calculation of the disposable income is provided in the appendix. For each hours of work option we then calculate the CES part of the utility function, $U_{i, j}^{C E S}\left(h_{j, k}\right)$, which is independent of the idiosyncratic parameter $\bar{h}_{i, j}$. With given values of $U_{i, j}^{C E S}\left(h_{j, k}\right)$ we can determine the critical values of $\bar{h}_{j, i}$ for those individuals who are indifferent between two adjacent working time categories. These critical values delimit individuals who work in the lower hours-of-work category from those who work in the upper category. We denote the critical value of $\bar{h}_{j, i}$ for household type $j$ between hours of work category $k$ and $k+1$ with $\bar{h}_{j, k, k+1}$ and calculate it as

$$
\bar{h}_{j, k, k+1}=\frac{h_{j, k}+h_{j, k+1}}{2}+\frac{U_{i, j}^{C E S}\left(h_{j, k}\right)-U_{i, j}^{C E S}\left(h_{j, k+1}\right)}{2 \beta_{j}} .
$$

If the CES utility for both hours-of-work options is the same, the critical value of $\bar{h}$ will lie exactly half way between both. If one CES utility is higher than the other, the critical value of $\bar{h}_{j}$ will be asymmetrical, and the extent of the asymmetry will 
be determined by the value of $\beta_{j}$. The critical values of $\bar{h}_{j}$ are crucial both for the calibration of the model (see Section 3) and the policy simulations. A change in the tax and transfer system will affect the disposable income and consumption of the households. This bears on the CES utilities and thus the relative attractiveness of the different working time options. The critical values of $\bar{h}_{j}$ adjust, which, depending on the distribution of the $\bar{h}_{j, i}$ within the household types, finally determines the frequencies of the different working time categories.

For couple households, working time is determined in an analogous manner. Each couple household can choose among 15 working time options (3 for the man, 5 for the woman). We disassemble the simultaneous maximisation problem of the household into two independent working time choices of the partners by assuming that when one partner chooses their optimal working time, they take the other partner's income and leisure to be constant at their conditional expected values given the benchmark probabilities. ${ }^{1}$ In this way, we obtain independent critical values of $\bar{h}$ for both partners.

Due to data restrictions in the microsimulation model that we use to calibrate the labour supply module, only about $60 \%$ of total labour supply is captured. Therefore, in the general equilibrium model, the labour supply module is complemented with an additional aggregate household with fixed labour supply, which accounts for the rest (see Section 4.1).

\footnotetext{
${ }^{1}$ The simultaneous maximisation of female and male working hours would encounter difficulties because multiple local maxima are possible. (Given that the woman works longer, it is optimal for the man to work less, and vice versa.) This would require an explicit comparison of absolute utility values, which doesn't match well with the overall mixed-complementarity set-up of the numerical model. Furthermore, it is likely to result in discontinuous reactions of the households, when they switch from one local equilibrium to another.
} 


\section{Calibration of the labour supply module}

The empirical calibration values for each household type are derived using the ZEW microsimulation model (Buslei and Steiner, 1999, Steiner and Jacobebbinghaus, 2003). The underlying labour supply parameters have been estimated with a logit model based on data from the German Socio-Economic Panel (SOEP). We work with three sets of parameters from this model: (1) the distribution of the 26 household types, (2) the distribution of household labour supply within each household type, (3) the simulated partial ${ }^{2}$ own-price elasticities of labour supply for each household type. The simulated elasticities are documented in Table 5 in the appendix. They are to be read as follows: If the gross wage for the first positive time category (38 hours per week) for married men in "CLLOK" couples rises by 10 per cent, the probability that these men supply 38-hours-per-week of labour will rise by 1.51 percentage points. (Observe that these elasticities cannot directly be compared to labour supply elasticities that are normally found in the empirical literature. The latter are estimated under the assumption that the wage rises uniformly in all hours-of-work categories, not only in one of them.)

In order to account for the empirical distribution of individuals into the single labour supply categories, we assume that the autonomous working-time preference parameter $\bar{h}$ is distributed over the interval $[0,70]$ in a stepwise uniform distribution. (70 hours is assumed to be the maximum amount that an individual can supply to the labour market.) The steps of this distribution coincide with the critical values of $\bar{h}$, which delimit households that fall into different working-hours categories. We assume that all individuals working $h_{k}$ hours in the benchmark situation are uniformly distributed between $\bar{h}_{k-1, k}$ and $\bar{h}_{k, k+1}$. These steps in the density distribution are

\footnotetext{
${ }^{2}$ Percentage point changes of the probabilities in relation to per cent changes in the wage.
} 
then held fixed in the subsequent counterfactual analysis. The stepwise uniform distribution is flexible enough to exactly reproduce the empirical working-hours distribution in the model. In the case of couple households, the density distribution to be adjusted is two-dimensional. It is composed of 15 cells, each of which has a uniform probability density.

Next, we calibrate the model so as to optimally reproduce the elasticities simulated with the microsimulation model. We determine analytically the values of these elasticities in the model by calculating how a rise in the wage in one workingtime category affects the disposable household income of households that supply labour in this category. Through the CES part of the utility function, the change in consumption leads to an adjustment of the critical values of $\bar{h}$. Some households characterised by values of $\bar{h}$ that are close to the critical values in the benchmark will change labour supply categories. However, as the density of the distribution of the $\bar{h}$ is discontinuous at the critical value, the elasticity of the model will be different whether we increase or lower the wage. We take the average of these two reactions to match the empirical elasticities,

$$
\varepsilon_{k}=w_{k} \frac{d C}{d w_{k}}\left(1-\alpha_{j}^{L}\right)\left(\frac{U_{j, h_{k}}^{C E S}}{C_{j, h_{k}}}\right)^{\frac{1}{\sigma_{l}}} \frac{f_{k-1}+2 f_{k}+f_{k+1}}{2 \beta_{j}},
$$

where $f_{k}$ is the density of $\bar{h}$ between $\bar{h}_{k-1, k}$ and $\bar{h}_{k, k+1}$, and $\varepsilon_{k}$ is the corresponding empirical elasticity.

In equation (3) we have three free parameters, $\alpha_{j}^{L}, \sigma_{j}$ and $\beta_{j}$. (For couples, the calibration procedure is the same, except that there are five parameters, $\alpha_{j}^{L}, \alpha_{j}^{f}, \sigma_{j}$, $\beta_{j}^{f}$ and $\beta_{j}^{m}$.) However, variations in these parameters have very similar and in the relevant range nearly linear effects on the elasticities. This means individual parameter values are not well identified when we solve the numerical problem of optimally adjusting to the empirical elasticities. Therefore, we arbitrarily fix the value of $\sigma_{j}$ for 
all households at 2, which stabilises the determination of the other parameter values. The values of the calibrated elasticities are only slightly affected by this measure. Table 5 in the appendix compares the elasticities that result from our calibration procedure with the simulated elasticities from the microsimulation model. The table makes clear that our model is fairly good in approximating the overall level of labour supply reactions. However, with respect to the ranking of the elasticities across the different working time categories, it is rather inflexible. Here one could think of alternative functional forms.

\section{An AGE framework with decentralised wage bargaining}

The labour supply module is embedded into a computable general equilibrium model of Germany ("PACE-L"). In this section, we focus on the wage determination module of PACE-L, which, through the wage bargaining mechanism, directly interacts with the labour supply decision of the households. The other parts of the model are only sketched. An extensive, algebraic model description and a summary of the data sources used for calibration can be found in Böhringer, Boeters and Feil (2002).

\subsection{Labour Market}

In each of 7 production sectors, wages are determined by sector-specific bargaining between an employers' association and a trade union. As is usual in the trade union literature (see e.g. Layard et al., 1991, Ch.2), we represent the bargaining outcome as the maximisation of a Nash function, which includes the objective functions of both parties and their respective fallback options. We adopt the "right to manage" 
approach: Parties bargain over wages, and firms decide over labour demand given the bargained wage. The labour demand reaction in turn is anticipated in the wage bargaining.

The Nash bargaining solution is obtained by solving

$$
\max _{w_{H, s}, w_{L, s}} \ln \Omega_{s}=\ln \pi_{s}+\rho_{H, s} \ln \Gamma_{H, s}+\rho_{L, s} \ln \Gamma_{L, s}
$$

where $\Omega_{s}$ : Nash maximand in sector $s, \pi_{s}$ : profits of representative firm, $\Gamma_{i, s}$ : union utility of workers of type $i(i=L, H), \rho_{i, s}$ : bargaining power of workers of type $i$, $w_{i, s}$ : producer wage for skill type $i$.

In each sector, the firm's objective is its profit, $\pi_{s}$. We assume that the firm's fallback option is no production and, thus, zero profits. The union represents two types of workers, high skilled and low skilled (indexed by $i$ ). For each skill type, the union's objective function is employment, $L_{i, s}$, times the value of a job, $V_{i, s}$, minus the value of unemployment, $V_{i, U}$ :

$$
\Gamma_{i, s}=L_{i, s}\left(V_{i, s}-V_{i, U}\right)
$$

As is customary in the search model literature (see e.g. Pissarides, 1990), $V_{i, s}$ and $V_{U, i}$ are calculated as value functions, which are defined recursively and then solved for their steady state values:

$$
\begin{aligned}
V_{i, s} & =\frac{1}{1+r}\left[A I E_{i, s}+\left(1-\mu_{s}\right) V_{i, s}+\mu_{s} V_{i, U}\right], \\
V_{i, U} & =\frac{1}{1+r}\left[A I U_{i}+\left(1-\lambda_{s}\right) V_{i, U}+\lambda_{s} V_{i, s}\right],
\end{aligned}
$$

where $r$ : discount rate, $\mu_{s}$ : separation rate in sector $s, \lambda_{s}$ : matching rate. $A I E_{i, s}$ is the average disposable income of an employed worker in sector $s$, where the average is calculated over all household types and positive hours-of-work categories. $A I U_{i}$ 
is the average disposable income of an unemployed worker, averaging over the cases of unemployment benefit and social assistance recipients. Note that $A I U_{i}$ and $V_{i, U}$ are independent of sectors. Unemployed workers are mobile between sectors and in equilibrium must be indifferent with regards to in which sector to search for a job. The $\lambda_{s}$ 's adjust so as to warrant this indifference (while the $\mu_{s}$ are exogenously fixed). As usual in dual-labour-market type models, this results in the relation that the higher the "surplus from working" is in a sector, the lower the matching rate must be (see Acemoglu 2001). By solving (5) and (6), we can express $V_{i, s}$ and $V_{i, U}$ as weighted averages of the expected incomes in the two labour market states.

Maximising the Nash objective (4) yields one first order condition (FOC) for each skill group and sector:

$$
\frac{\partial \pi_{s}}{\partial w_{i, s}} \frac{1}{\pi_{s}}=\rho_{H, s} \frac{\partial \Gamma_{H . s}}{\partial w_{i, s}} \frac{1}{\Gamma_{H, s}}+\rho_{L, s} \frac{\partial \Gamma_{L, s}}{\partial w_{i, s}} \frac{1}{\Gamma_{L, s}}
$$

We use uncompensated own- and cross-price labour demand elasticities, $\eta_{i j}$, to write the FOCs in a compact form. Both bargaining parties know that firms will increase their output price when wages rise, leading to a fall in output. For collective bargaining, the relevant output price elasticity is the elasticity of industry output, not the individual firm's output. The nesting structure of both production and consumption requires a numerical approximation of the relevant price elasticities. We calculate the latter at the benchmark point and use these values as parameters in subsequent policy counterfactuals.

For low-skilled labour the FOC in compact form then is

$$
\frac{-L_{L, s}\left(1+t_{l, s}\right)}{\pi_{s}}=\rho_{L, s}\left(\frac{\eta_{L L, s}}{w_{L, s}}+\frac{1-t_{w m, L}}{\tilde{w}_{L, s}-r V_{U, L}}\right)+\rho_{H, s} \frac{\eta_{H L, s}}{w_{H, s}},
$$

where $t_{l, s}$ : social security contribution as a payroll tax, $w_{i, s}$ : wage gross of wage income taxes, $\tilde{w}_{i, s}$ : consumer wage, $t_{w m, i}:$ total marginal effect of tax and transfer 
system, $r$ : capital market discount rate. The FOC for high-skilled labour has an analogous form.

We assume that the trade union is utilitarian with respect to the different household types. The marginal tax rates and the values of the states of employment and unemployment that appear in (8) are therefore calculated as weighted averages over all households. In turn, the wage that results from bargaining in general equilibrium is used to derive the income positions of all households in all possible labour market states. In order to preserve continuity of the model, this dependence is linearly approximated. We calculate an average and a marginal rate of the total tax and transfer effects for each household and labour market state in the benchmark. These are treated as parameters in the counterfactual policy simulations.

The two labour markets for low and high skilled labour are balanced by aggregating on the demand side over sectors and on the supply side over household types. We assume that the structure of labour input with respect to household types is uniform across sectors. The households captured by the microsimulation model include all households with flexible time allocation and observable hours of work, which is about $60 \%$ of total labour supply. Pensioners, students, women on maternity leave, civil servants and the self-employed are excluded in the microsimulation model. In the general equilibrium model, they are represented by an additional aggregate household with fixed labour supply. Household-specific unemployment rates are aggregated into economy-wide unemployment per skill group. Changes in aggregate unemployment are distributed among household types in proportion to their benchmark unemployment. 


\subsection{Firms}

In each production sector, a representative firm produces a homogenous output. The production function is of the nested constant-elasticity-of-substitution (CES) type, combining intermediate inputs, capital and labour of the two skill types. The value shares of the various inputs are calibrated according to the input-output table for Germany. Factor demand elasticities are taken from Falk and Koebel (1997). Each individual firm is assumed to be small in relation to its respective sector. All firms in one sector interact through monopolistic competition, i.e. they produce individual variants of the sectoral output good that attract different consumers. This means that firms can exploit market power in their respective market segment. Producer output prices then consist of costs (of the three primary inputs as well as intermediary inputs) plus a fixed mark-up.

Cost minimisation yields demand functions for the primary factors at the sectoral level and corresponding uncompensated (own and cross) price elasticities for labour that are used in the Nash bargaining FOCs (8). Capital and labour are mobile across sectors. The market for capital is perfectly competitive. Our basic assumption is that capital is internationally immobile, which reflects a short- to medium-run model horizon. Labour mobility is modelled in a dual-labour-market fashion. In the presence of cross-sector wage differentials, hypothetical sector specific unemployment rates (application queues) are adjusted so as to make the unemployed indifferent between sectors.

\subsection{Private Households}

We distinguish the 26 worker households described in the appendix A.1, one dummy household with fixed labour supply, which accounts for the households not covered 
by the microsimulation model, and a capitalist household. The capitalist household receives all capital and profit income. Capitalists decide over consumption and investment according to the approach of Ballard et al. (1985). Their utility function is calibrated to empirical saving elasticities (Bernheim 2001). Worker households do not save.

The structure of consumption is assumed to be identical across all households. Aggregate consumption is distributed among the different consumption goods according to a CES function. Each consumption good is composed of the Armington goods (see Section 4.5) in fixed proportions given by the value shares from the Z-matrix of national accounting. In the same manner, the investment good is a fixed-coefficient composite of all Armington goods.

\subsection{Government}

The main focus in the model of this paper is on the complex tax and transfer system for private households. The detailed budget constraints of the households are calculated in a special programme module (see the appendix A.4). The budget constraints are then linearly approximated through two sets of parameters: an average and a marginal tax and transfer rate for each household type in each labour supply category and each labour market state (employed, unemployed with or without unemployment benefit entitlement).

Apart from the taxes and transfers for the private households, the government collects the following taxes: a uniform capital input tax, a profit tax and an output tax in production, and a differentiated consumption tax on all consumption commodities. Tax rates are calibrated to correspond to the tax revenue statistics of the benchmark year 1997. The government budget contains the revenue from all these 
taxes, the public purchases of goods and the balance of payments surplus or deficit. The public budget is balanced by a hypothetical lumpsum transfer. We fully allocate this transfer to the capitalist household in order to circumvent the question of how to distribute it among the various worker household types.

\subsection{Foreign Trade}

Domestically produced goods are converted through a constant-elasticity-of-transformation function into specific goods destined for the domestic market and the export market, respectively. By the small-open-economy assumption, export and import prices in foreign currency are not affected by the behaviour of the domestic economy. Analogously to the export side, we adopt the Armington assumption of product heterogeneity for the import side. A CES function characterises the choice between imported and domestically produced varieties of the same good (elasticities are taken from Welsch 2001). The Armington good enters intermediate and final demand. Foreign closure of the model is warranted through the balance-of-payments constraint. The flexible exchange rate adjusts so as to leave the benchmark balance of payments deficit (or surplus) unchanged in terms of world market prices.

\section{Illustrative Simulations:}

\section{Cuts in the social assistance payments}

To illustrate the working mechanisms of the model, we present simulations of two very simple policy measures that both cut the social assistance payments, but to a different extent. The simulations (especially the first one) are not meant to represent a realistic policy reform, but to produce model results that lend themselves to a 
straightforward interpretation. These basic effects can then serve to explain the outcomes of more complex policy reforms. We investigate realistic policy reform scenarios in the companion paper Boeters, Gürtzgen and Schnabel (2003).

In Scenario 1, the basic social assistance (SA) rate ("Regelsatz") is cut by 50 per cent for all household members (adults and children). Housing and heating subsidies as well as transfer withdrawal regulations remain unchanged. (See the appendix A.5 for some more details about the German SA system.) In Scenario 2, the basic SA rate is cut by 50 per cent only for adult SA recipients who are able to work. Single parents with more than one child and women in couple households with more than one child are assumed to be unable to work due to child care responsibilities. For those persons the benchmark basic SA rate remains unchanged. Compared to Scenario 1, in Scenario 2 households with children are therefore less likely to be affected by the reform, since the basic SA rate of children remains unchanged and couple households with more than 1 child only face a reduction in the basic SA rate of the household head.

Compared to a pure labour supply analysis, we are especially interested in two kinds of effects. First, how will the wages react to changes in the labour supply, and how they feed back to the labour supply decision itself? Second, what the effects of the necessary budget balancing are? In general, the policy measure in question, taken for itself, will result in a deficit or surplus of the public budget. This results from both direct effects (lower SA payments in our case) and indirect effects (possibly higher wage income tax revenues due to higher employment). In our simulations, we assume that the net effect of these tax revenue changes is balanced by an adjustment of the general income tax. We uniformly raise or cut the marginal tax rate on profits, capital and labour income so that public expenditures remain unchanged.

We first describe in detail the results from Scenario 1, where SA payments are 


\begin{tabular}{||l|cc|cc||}
\hline \hline \multirow{2}{*}{ Variable } & \multicolumn{2}{|c|}{ Sc.1 } & \multicolumn{2}{c||}{ Sc.2 } \\
& low & high & low & high \\
\hline labour supply, hh in sample & 0.92 & 0.47 & 0.75 & 0.38 \\
labour supply, all hh & 0.60 & 0.31 & 0.48 & 0.24 \\
unemployment rate & -0.25 & -0.08 & 0.00 & -0.02 \\
aggregate employment & 0.88 & 0.39 & 0.48 & 0.27 \\
average producer wage & -1.19 & -1.03 & -0.65 & -0.70 \\
aggregate wage income & -0.32 & -0.64 & -0.17 & -0.44 \\
interest rate & 1.98 & 1.32 \\
income share of labour & -0.41 & -0.27 \\
income share of capital & 0.39 & 0.26 \\
profit share & 0.02 & 0.01 \\
aggregate consumption & -0.35 & -0.24 \\
aggregate investment & 2.16 & 1.45 \\
gross domestic product & 0.21 & 0.14 \\
income tax adjustment & -0.30 & -0.21 \\
\hline \hline
\end{tabular}

Table 1: Macroeconomic Scenario Results

cut regardless of the individuals' ability to work. Column "Sc.1" in Table 1 reports changes in some important macroeconomic variables. Changes are normally given in per cent. For those variables that are a fraction themselves (income shares, unemployment rates), changes are in percentage points. Most effects in Table 1 can be interpreted in a straightforward way. Labour supply rises as we would expect when the option of not working becomes less attractive. When we focus on the part of the working population that is captured in our labour supply module, the labour supply increases are $0.9 \%$ (low skilled) and $0.5 \%$ (high skilled). It is plausible that low 
skilled workers show a much more pronounced effect than the high skilled, because high-skilled workers have higher opportunity costs and use the option of not working less frequently. Together with the last third of the labour force, whose labour supply is assumed to be fixed, we arrive at aggregate labour supply effects of $0.6 \%$ and $0.3 \%$, respectively. Through the wage bargaining system, this higher labour supply translates into both lower unemployment (decreases in the unemployment rate by 0.3 and 0.1 percentage points for low and high skilled) and lower wages. The driving force for the wage cut is that the fallback option of the trade unions decreases with lower SA payments and - prior to wage adjustment - higher unemployment. In our simulations the relative decrease in wages is even higher than the relative increase in employment (producer wages go down by $1.2 \%$ and $1.0 \%$, respectively). This means that aggregate labour income, and also the functional income share of labour, shrinks in spite of higher employment.

As we assume the capital stock to be fixed within the period of labour supply adjustment, the interest rate increases due to higher labour input, and so does the income share of capital. This produces two effects that add to a shift in the spending pattern from consumption (which in fact decreases) to investment. A higher interest rate makes future consumption relatively more attractive, and income is redistributed from worker households to capital owners, who have a higher saving rate.

With respect to the public budget, there is initially a tax revenue surplus, which results both from the cut in the social benefit payments and in higher overall tax revenues from all sources. (But observe that wage income tax revenue goes down because of the wage cuts.) This makes it possible to lower the general marginal income tax rate by 0.3 percentage points.

We now turn from the aggregate effects to the labour supply reactions of the 


\begin{tabular}{||l|ccc|ccc||}
\hline \hline \multirow{2}{*}{ Group } & \multicolumn{3}{|c|}{ Sc.1 } & \multicolumn{3}{c||}{ Sc.2 } \\
& PR & AWT & TLS & PR & AWT & TLS \\
\hline married men & 0.61 & -0.06 & 0.59 & 0.51 & -0.05 & 0.49 \\
married women & 0.49 & -0.47 & 0.28 & 0.41 & -0.42 & 0.23 \\
singles & 0.72 & -0.15 & 0.58 & 0.59 & -0.18 & 0.45 \\
low skilled & 0.75 & -0.04 & 0.92 & 0.60 & -0.04 & 0.75 \\
high skilled & 0.57 & -0.06 & 0.47 & 0.48 & -0.05 & 0.38 \\
\hline \hline
\end{tabular}

PR: participation rate, AWT: average working time,

TLS: total labour supply (in hours)

Table 2: Simulation Results for Different Subsets of Households

different households types. Table 2 shows the changes in participation rates, average working time and total labour supply (measured in hours) for different subsets of households. For all households, there is an increase in labour supply. This overall effect has two components that work in opposite directions. On the one hand, the participation rate increases because of the lower attractiveness of the no-laboursupply option. This increase in the participation rate is between half and three quarters of a percentage point. The lowest increase is observed for married women, while low skilled workers (who, of course, partly overlap with married women) react most strongly. On the other hand, the average working time of those who supply work falls. This is a direct consequence of the basic model setup, where household heterogeneity is modelled as a linear preference parameter over working time. This means that all households who change from non-participation to participation in the labour market supply labour in the lowest positive time category. The average amount of labour time supply per household thus decreases. This decrease is lowest for married men, because they choose only between two working time categories 
that are close to the average (see Table 4 in the appendix). By contrast, married women and singles switch into working time categories that are considerably below the average.

With respect to the overall change in labour supply, we can observe the following differences between the household groups. Differentiated by marital status, the labour supply of married men and singles rises considerably more than that of married women. This can again mainly be explained by the construction of the working time categories, where only married women have the option to switch into a working time category with few hours. With respect to the skill groups, the supply of low skilled work increases more than that of high skilled work. The entries for total labour supply of low and high skilled workers in Table 2 match those in Table 1.

Turning to Scenario 2 ("Sc.2" in Tables 1 and 2), where social assistance payments are cut only for those individuals who are considered able to participate in the labour market, we see that, in general, economic effects are weakened. When we compare Columns "Sc.1" and "Sc.2" in Table 2, we see that labour supply effects are reduced virtually uniformly across households. This is because the main effect is through the SA payments for children, which (for couples) affect the labour supply decision of both partners to the same extent. Compared to this effect, the differential treatment of men and women in couples is of minor importance.

The lower labour supply effects translate into a general mitigation of macroeconomic changes in Table 1. In addition, both the wage and unemployment effects for the two skill groups are reversed. The fall in the producer wage for high skilled workers is higher than that for low skilled workers. Consequently, unemployment is reduced to a higher extent for high skilled workers. This is because those individuals that benefit from the mitigation of the SA cuts in Scenario 2 are disproportionately more often low than high skilled. In general, however, unemployment changes are 
very small in Scenario 2.

On a macroeconomic level, the mitigation of the cuts in SA payments amounts to roughly one third of the effects in Scenario 1. GDP increases by $0.14 \%$ instead of $0.21 \%$, and the income tax cut that can be financed by the tax surplus through this reform is 0.21 percentage points instead of 0.30 .

\section{Conclusions}

In this section we summarise the main advantages of our modelling approach compared to CGE models with a representative household on the one hand and microsimulation models without macroeconomic repercussions on the other. We then turn to some potential weaknesses of the current version of our model and briefly sketch options of extending the model.

In comparison to a CGE model with a representative household, the following features of our model deserve emphasis:

- The extensive and the intensive margin of labour can be distinguished. Changes in total labour supply are broken down into changes in the participation rate and changes in the average hours of work supplied, as in Table 2 in Section 5.

- For each individual household a complex budget constraint is formulated, so that the details of national tax and transfer systems can be integrated in the model. This is especially important for couple households, for which tax and transfer rules depend on the household composition as well as the labour market status of both partners. 
- The separation of different household types and the integration of their individual budget constraints allows us to analyse policy reforms that concern the demographical details of the household composition. (E.g. differential treatment of households with and without children in our illustrative simulations.)

- The effects of tax and transfer policy changes on different household types can be analysed. In our simulation, we are able to report differentiated labour supply changes for married and unmarried workers, for high and low skilled workers and for households with and without children.

A comparison of our model to microsimulation models of labour supply highlights the following differences:

- Complex interactions in the whole economy are captured. Labour supply changes affect different sectors of the economy differently, with sectoral factor demand and international trade consequences. The public budget is affected both directly through reform policies and indirectly through their consequences throughout the whole economy.

- The interaction of labour supply and wage formation is identified as the main feedback channel. Changes in the transfer payments alter the union's fallback option in the firm-union wage-bargaining setup both directly and indirectly through labour supply effects. The resulting wage changes in turn affect the labour supply decision.

- The recycling of additional (or lacking) tax revenue is an integral part of the economic analysis. In our illustrative cases there is a primary budget surplus from two sources: lower public expenses for social assistance payments and higher tax revenues due to higher overall economic activity. This makes it 
possible to lower the income tax, which again produces general equilibrium effects. Alternative ways of recycling the tax revenue can be analysed with the same overall setup.

Although in principle, our model combines important features from both numerical general equilibrium modelling and microsimulation, there are still a number of potential shortcomings of the current approach. Their consequences must be further analysed and compared with those of alternative modelling strategies:

- As we use an a-priori disaggregation of households, this leaves us with some inflexibility. The appropriate aggregation structure might vary with the policy measure that is analysed. The aggregation structure chosen in this paper is well suited for policies that are differentiated along the lines of household composition, number of children or type of labour supplied (high or low skilled). Other differentiation criteria, which are in principle available in the basic data set (e.g. age of the individuals, home region) and might be important for other policy measures, are not mirrored in our concrete aggregation.

- The functional form chosen to reproduce the labour-leisure choice imposes some restrictions on the labour supply behaviour. The parameterisation is such that simulated elasticities can only be approximated to a certain degree (see the comparison of simulated and calibrated elasticity values in the appendix). More importantly, the function used to simulate the elasticities (logit) and the function in our model have incompatible consequences for some reactions of the households. If one option becomes less attractive and becomes thus less frequently chosen, in a logit setting this means that all other options become proportionally more frequent. In contrast, with the function presented in Section 2, only neighbouring options are affected. 
- In the current version of the model, a local, linear approximation of the households' budget constraints are calculated in a special procedure and then used as the only budget information in the general equilibrium model. This means that there are slight approximation errors, especially if the household is close to a point where its budget constraint is kinked due to a non-differentiable taxtransfer schedule. In principle, it is possible to fully integrate the non-linear budget constraints into the general equilibrium setting. However, this would require the formulation of a complementarity condition for each piecewise defined section of the budget constraint. We do not think that this effort would pay off in considerably increased simulation accuracy.

Given the listed advantages and possible restrictions of the present model version, we see three principle routes of future research. The first option is to use the model as it is to simulate realistic policy reforms. In this way, we see which of the possible limitations turn out to be relevant in practice. This is done for different versions of social security reform in Germany in Boeters, Gürtzgen and Schnabel (2003). Second, we could try alternative formulations of important model parts: either experiment with other functional forms for the labour-leisure choice or integrate the full non-linear households' budget constraints into the model. Third, one fundamental revision of the model setup would be to dispense with intermediate a-priori aggregation and integrate the logit microsimulation model as a whole into the general equilibrium framework. However, this would mean that each individual household could only make a decision that is structured in a very simple way. Otherwise we would probably approach the limits of what is currently numerically tractable. The issue of the most appropriate aggregation level can only be answered with a concrete policy application in mind. 


\section{References}

[1] Acemoglu, Daron (2001): Good Jobs versus Bad Jobs, Journal of Labor Economics, 19, 1-21

[2] Baekgaard, Hans and Martin Robinson (1997): Integrating Microsimulation and Economy-wide Models: Estimating the Distributional Impact of Changes in the Australian Economy, Paper presented to the Conference of Economists Hobart, 1997

[3] Ballard, Charles L., Don Fullerton, John B. Shoven and John Whalley (1985): A General Equilibrium Model for Tax Policy Evaluation, The University of Chicago Press, National Bureau of Economic Research

[4] Bernheim, Douglas B. (1999): Taxation and Saving, NBER Working Paper 7061

[5] Blundell, Richard and Thomas MaCurdy (1999): Labor Supply: A Review of Alternative Approaches, in: Ashenfelter, Orley and David Card (eds.): Handbook of Labor Economics, Vol. 3, Amsterdam (Elsevier), 1559-1695

[6] Boeters, Stefan, Nicole Gürtzgen and Reinhold Schnabel (2003): Reforming Social Welfare in Germany - An Applied General Equilibrium Analysis, ZEW Discussion Paper 03-70, Mannheim

[7] Böhringer, Christoph, Stefan Boeters and Michael Feil (2002): Taxation and Unemployment: An Applied General Equilibrium Approach for Germany, ZEW Discussion Paper 02-39, Mannheim

[8] Bourguignon, François, Anne-Sophie Robilliard and Sherman Robinson: Representative versus real households in the macro-economic modelling of inequality, DIAL, Document de Travail, DT/2003-10 
[9] Bovenberg, A. Lans, Johan J. Graafland and Ruud A. de Mooij (2000): Tax reform and the Dutch labor market : an applied general equilibrium approach, Journal of Public Economics, 78, 193-214

[10] Bundesministerium für Wirtschaft und Technologie (2002): Reform des Sozialstaats für mehr Beschäftigung im Berreich gering qualifizierter Arbeit, Dokumentation Nr. 512

[11] Buslei, Hermann and Viktor Steiner (1999): Beschaeftigungseffekte von Lohnsubventionen im Niedriglohnbereich, Baden-Baden: Nomos

[12] Cogneau, Denis and Anne-Sophie Robilliard (2000): Growth, distribution and poverty in Madagascar: Learning from a microsimulation model in a general equilibrium framework, International Food Policy Research Institute, TMD Discussion Paper 61

[13] Davies, James B. (2003): Microsimulation, CGE and Macro Modelling for Transition and Developing Economies, University of Western Ontario, mimeo

[14] Dixon, Peter, Michael Malakellis and G.A. Meagher (1996): A Microsimulation/Applied General Equilibrium Approach to Analysing Income Distribution in Australia: Plans and Preliminary Illustration, COPS, Working Paper IP-67

[15] Falk, Martin, and Bertrand Koebel (1997): The Demand of Heterogeneous Labour in Germany, ZEW Discussion Paper 97-28, Mannheim

[16] Graafland, Johan J., Ruud A. de Mooij, André G.H. Nibbelink and Ate Nieuwenhuis (2001): MIMICing Tax Policies and the Labour Market, Amsterdam: Elsevier 
[17] Jacobebbinghaus, Peter, and Viktor Steiner (2003): Dokumentation des Steuer-Transfer-Mikrosimulationsmodells STSM, ZEW Dokumentation 03-06, Mannheim

[18] Kehoe, Patrick J., and Timothy J. Kehoe (1994): A Primer on Static Applied General Equilibrium Models, Federal Reserve Bank of Minneapolis Quarterly Review, Spring

[19] Layard, Richard, Stephen Nickell and Richard Jackman (1991): Unemployment. Macroeconomic Performance and the Labour Market, Oxford: Oxford University Press

[20] Pereira, Alfredo M., and John B. Shoven (1992), Survey of Dynamic Computational General Equilibrium Models for Tax Policy Evaluation, Journal of Policy Modeling, 10, 401-426

[21] Pissarides, Christopher A. (1990): Equilibrium unemployment theory, Oxford: Basil Blackwell

[22] German Council of Economic Experts (Sachverständigenrat zur Begutachtung der gesamtwirtschaftlichen Entwicklung, 2002): Zwanzig Punkte für Beschäftigung und Wachstum, Wiesbaden

[23] Shoven, John B., and John Whalley (1984): Applied General-Equilibrium Models of Taxation and International Trade: An Introduction and Survey, Journal of Economic Literature, 22, 1007-1051

[24] Shoven, John B., and John Whalley (1992), Applying General Equilibrium, Cambridge: Cambridge University Press 
[25] Sinn, Hans-Werner, Christian Holzner, Wolfgang Meister, Wolfgang Ochel and Martin Werding (2002): Aktivierende Sozialhilfe: Ein Weg zu mehr Beschäftigung und Wachstum, ifo Schnelldienst, Nr. 9

[26] Steiner, Viktor, and P. Jacobebbinghaus. (2003): Reforming Social Welfare as we know it? A Microsimulation Study for Germany, ZEW Discussion Paper 03-33, Mannheim

[27] van Soest, Arthur (1995): Structural models of family labor supply : a discrete choice approach, Journal of human resources, 30, 63-88

[28] Welsch, Heinz (2001): Armington Elasticities and Product Diversity in the European Community: A Comparative Assessment of Four Countries, Working Paper, University of Oldenburg

[29] Weyant, John P. (ed) (1999), The Costs of the Kyoto Protocol: A Multi-Model Evaluation, The Energy Journal, Special Issue 


\section{A Appendix}

\section{A.1 Household classification for labour supply module}

\begin{tabular}{||l|l||}
\hline \hline Abbreviation & Definition \\
\hline CijxK & couple, woman skill group i, man skill group j, x children \\
Mi0 & male single, skill group i, no children \\
Wi0 & female single, skill group i, no children \\
xKi & single (male or female), skill group i, x children \\
\hline \hline
\end{tabular}

$\mathrm{i}=\mathrm{L}$ (low skilled), $\mathrm{H}$ (high skilled), $\mathrm{x}=0,1,2$ or more

Table 3: Household Disaggregation

\section{A.2 Working hours options for different household types}

\begin{tabular}{||l|l|l|l|l|l||}
\hline \hline Individual & \multicolumn{5}{|c||}{ Hours Options } \\
\hline men, married or single without children & 0 & & & 38 & 49 \\
men, single with children & 0 & 15 & 30 & 38 & 47 \\
women, single & 0 & 15 & 30 & 38 & 47 \\
women, married & 0 & 9.5 & 24 & 38 & 47 \\
\hline \hline
\end{tabular}

Table 4: Discrete Working Hours by Household Types 


\section{A.3 Comparison of simulated and calibrated elasticities}

\begin{tabular}{|c|c|c|c|c|c|c|c|c|c|c|c|c|}
\hline \multirow[b]{2}{*}{ Household } & \multicolumn{4}{|c|}{ Elasticities Men } & \multicolumn{8}{|c|}{ Elasticities Women } \\
\hline & $1(\mathrm{~s})$ & $1(\mathrm{c})$ & $2(\mathrm{~s})$ & $2(\mathrm{c})$ & $1(\mathrm{~s})$ & $1(\mathrm{c})$ & $2(\mathrm{~s})$ & $2(\mathrm{c})$ & $3(\mathrm{~s})$ & $3(\mathrm{c})$ & $4(s)$ & $4(\mathrm{c})$ \\
\hline CLLOK & 1.51 & 1.83 & 1.67 & 1.02 & 0.07 & 0.25 & 0.56 & 0.29 & 0.76 & 0.75 & 0.29 & 0.50 \\
\hline CLHOK & 4.14 & 5.15 & 4.81 & 3.26 & 0.19 & 0.67 & 1.33 & 0.90 & 1.72 & 1.52 & 0.82 & 0.76 \\
\hline CHLOK & 3.32 & 4.27 & 4.06 & 2.77 & 0.22 & 0.42 & 1.46 & 1.45 & 2.44 & 2.25 & 1.56 & 1.23 \\
\hline СHHOK & 3.61 & 4.60 & 4.58 & 3.14 & 0.20 & 0.57 & 1.33 & 1.42 & 2.28 & 2.39 & 1.53 & 1.14 \\
\hline CLL1K & 1.27 & 1.62 & 1.72 & 1.04 & 0.05 & 0.29 & 0.37 & 0.27 & 0.28 & 0.42 & 0.07 & 0.21 \\
\hline CLH1K & 3.41 & 4.44 & 4.64 & 3.07 & 0.15 & 0.76 & 0.93 & 0.69 & 0.84 & 0.59 & 0.25 & 0.19 \\
\hline CHL1K & 2.55 & 3.47 & 3.82 & 2.69 & 0.25 & 0.51 & 1.00 & 0.74 & 1.04 & 0.74 & 0.36 & 0.27 \\
\hline CHH1K & 3.43 & 4.45 & 4.69 & 3.24 & 0.24 & 0.88 & 1.23 & 1.24 & 1.50 & 1.31 & 0.73 & 0.48 \\
\hline CLL2K & 1.44 & 1.79 & 1.86 & 1.30 & 0.06 & 0.47 & 0.57 & 0.15 & 0.58 & 0.08 & 0.23 & 0.02 \\
\hline CLH2K & 2.49 & 3.43 & 3.70 & 2.18 & 0.13 & 0.66 & 0.77 & 0.44 & 0.65 & 0.28 & 0.21 & 0.07 \\
\hline CHL2K & 2.04 & 2.78 & 3.12 & 2.03 & 0.14 & 0.45 & 0.75 & 0.70 & 0.60 & 0.57 & 0.17 & 0.16 \\
\hline CHH2K & 3.79 & 4.85 & 5.09 & 3.61 & 0.26 & 0.91 & 1.03 & 0.90 & 1.13 & 0.75 & 0.53 & 0.26 \\
\hline CLL3K & 1.00 & 0.55 & 1.50 & 1.53 & 0.06 & 0.47 & 0.21 & 0.19 & 0.11 & 0.08 & 0.02 & 0 \\
\hline CLH3K & 2.69 & 3.56 & 3.97 & 2.62 & 0.06 & 0.69 & 0.43 & 0.31 & 0.22 & 0.14 & 0.05 & 0 \\
\hline CHL3K & 2.49 & 2.57 & 2.94 & 2.75 & 0.18 & 0.85 & 1.06 & 0.45 & 1.15 & 0 & 0.39 & 0 \\
\hline СНH3K & 4.23 & 5.42 & 5.62 & 3.83 & 0.25 & 0.81 & 0.89 & 1.01 & 0.83 & 0.66 & 0.32 & 0.06 \\
\hline ML0 & - & - & - & - & - & 0.04 & - & 0.81 & 1.54 & 1.75 & 1.98 & 0.88 \\
\hline МH0 & - & - & - & - & - & 0.02 & - & 0.84 & 1.55 & 1.80 & 2.09 & 0.94 \\
\hline WL0 & - & - & - & - & 0.43 & 0.50 & 2.15 & 2.04 & 3.08 & 3.09 & 1.61 & 1.75 \\
\hline WH0 & - & - & - & - & 0.38 & 0.14 & 2.34 & 2.44 & 3.28 & 3.88 & 3.08 & 1.84 \\
\hline $1 \mathrm{KL}$ & - & - & - & - & 0.29 & 0.10 & 1.16 & 1.17 & 1.64 & 1.80 & 1.14 & 0.80 \\
\hline $1 \mathrm{KH}$ & - & - & - & - & 0.31 & 0.26 & 1.88 & 2.13 & 2.41 & 2.58 & 1.87 & 1.15 \\
\hline $2 \mathrm{KL}$ & - & - & - & - & 0.09 & 0.23 & 0.09 & 0 & 0.80 & 0.62 & 0.83 & 0 \\
\hline $2 \mathrm{KH}$ & - & - & - & - & 0.19 & 0.36 & 1.48 & 1.96 & 1.97 & 1.85 & 1.62 & 0.65 \\
\hline $3 \mathrm{KL}$ & - & - & - & - & 0.06 & 0.35 & 0.18 & 0 & 0.93 & 0 & 0.54 & 0 \\
\hline $3 \mathrm{KH}$ & - & - & - & - & 0.06 & 0.21 & 0.43 & 0 & 0.47 & 0.48 & 0.44 & 0.49 \\
\hline
\end{tabular}

1, 2, 3, 4: positive time categories, (s): simulated elasticities, (c): calibrated elasticities

elasticity values are to be read like this: change of labour supply probability in one category in percentage points as a reaction to a 10 per cent change of the wage in the respective category

Table 5: Partial Labour Supply Elasticities 


\section{A.4 The formulation of the individual household's budget constraint}

Gross monthly earnings are obtained by multiplying the gross hourly wage with monthly hours of work corresponding to the respective category of weekly labour supply. As we distinguish low and high-skilled labour, gross individual income does not only depend on the chosen category of hours worked, but also on the individual qualification. Low-skilled workers are defined as persons without any formal vocational training, whereas individuals holding a vocational or university degree are assumed to be high-skilled. Gross hourly wages are assumed uniform at $10.8 €$ for low skilled and $14.3 \notin$ for high skilled. These are average wages for the respective qualification levels in the German SOEP for the year 2000.

To obtain net earnings per month, income taxes and social security contributions are deducted from gross monthly earnings. The share in social security contributions borne by employees is taken to amount to 20 per cent of gross monthly earnings. At present, gross monthly earnings of $400 €$ are exempted from social security contributions. Income taxes are calculated on the basis of taxable income, which is obtained by substracting a standard deduction from gross earnings. To determine income taxes paid by each household type, we apply the present German income tax schedule to taxable earnings. For couple households, income tax legislation allows for marital income splitting: According to this method, the tax schedule is applied to half of the joint taxable income, while the resulting tax amount is doubled to obtain total income taxes paid by the couple.

Finally, disposable monthly earnings are obtained by adding transfer payments to net monthly labour earnings The most important transfer payments in Germany include unemployment insurance ("Arbeitslosengeld"), unemployment assis- 
tance ("Arbeitslosenhilfe"), social assistance ("Sozialhilfe"), housing benefits ("Wohngeld") and child benefits ("Kindergeld"). In our model, we account for unemployment benefits and assistance, social assistance and child benefits, while housing benefits are neglected.

In Germany, unemployment benefits (UB) are available for persons who have paid contributions to the statutory unemployment insurance for a minimum of one year. In particular, the duration of unemployment benefits depends on the unemployed person's former labour market experience and age. The monthly amount received equals a constant fraction of previous net monthly earnings. At present, the replacement rate for persons without children is 60 per cent and for persons with children 67 per cent. Unemployment benefits are not means-tested. The entitlement to unemployment benefits is thus completely independent from the labour or transfer income received by the respective spouse.

For those persons who don't have enough experience to obtain unemployment benefits or who have exhausted their unemployment benefits unemployment assistance (UA) and social assistance (SA) become relevant. The replacement rate for UA payments for persons without children is 53 per cent and for persons with children 57 per cent. In contrast to unemployment benefits, both welfare payments are means-tested, i.e. payments are reduced if either the unemployed person or remaining household members receive other incomes. While UA is only available for those persons who have exhausted their unemployment benefits, eligibility for SA does not require any former entitlement to unemployment benefits. Our model takes into account the means-tested nature of SA payments, but neglects the means-tested nature of UA payments. To incorporate the different transfer components in our model, we proceed as follows: first, we assign SA payments to all voluntarily unemployed singles and to those couple households whose adult members are both voluntarily 
unemployed $^{3}$. Second, for positive hours of labour supply we distinguish three labour market states: a person who supplies a positive number of hours worked may be employed, which will be denoted as state $(e)$. If the individual does not find a job and becomes involuntarily unemployed, he or she may either be entitled to UB or UA (b) or receive SA payments $(n)$. In a static model, we are not able to determine the entitlement to UB or UA due to former contributions to the statutory unemployment insurance. Instead, we assume that a person who becomes unemployed is entitled to unemployment benefits or unemployment assistance with an exogenous given probability $P_{U}$ and receives SA payments with probability $\left(1-P_{U}\right)$. In the former case, UB and UA payments are determined by the replacement ratio of the net income that corresponds to the chosen category of hours of labour supplied. More specifically, this replacement ratio is defined as a weighted average of UB and UA replacement rates where the weights are the respective empirical shares of persons entitled to UA or UB. SA payments, in contrast, do not depend on the category of hours supplied in the labour market.

The distinction of three labour market states requires that the value of disposable income for a particular category of working time has to be calculated as an expected value. For singles, the expected value of the disposable income for a particular category of hours of work supplied is determined as a weighted average of the disposable income values in the three labour market states $(e, b$ and $n)$, with the respective probabilities, $P(i), i=e, b, n$, as weights:

\footnotetext{
${ }^{3}$ For each household type, we split up those individuals that actually do not work into voluntarily and involuntarily unemployed in order to obtain household specific unemployment rates and nonparticipation rates. The shares of involuntarily unemployed persons are calibrated so as to match the resulting aggregate skill-specific unemployment rates with their empirical values in 2000 (IAB 2002).
} 


$$
E\left(y\left(h_{k}\right)\right)=\sum_{i=e, b, n} P(i) y^{D}\left(h_{k}, i\right), \quad i=e, b, n
$$

More specifically, we have $P(w)=(1-u), P(b)=u P_{U}$ and $P(n)=u\left(1-P_{U}\right)$, with $u$ representing the (household type specific) unemployment rate. For couples, the expected disposable income for a particular combination of hours of work is determined by the weighted average of disposable incomes corresponding to the 9 combinations of labour market states:

$$
E\left(y^{d}\left(h_{k}^{f}, h_{l}^{m}\right)\right)=\sum_{i, j=e, b, n} P(i) P(j) y^{D}\left(h_{k}^{f}, h_{l}^{m}, i, j\right), \quad i, j=e, b, n
$$

We make the simplifying assumption that spouses decide on their optimal working time based on the average disposable income that results from the different hours categories open to their partner. I.e., the expected disposable income determining the average consumption level for a particular category of hours worked $k$ in eq. (10) is given by

$$
\begin{aligned}
& E\left(y^{d}\left(h_{k}^{f}\right)\right)=\sum_{l} P\left(h_{k}^{f}, h_{l}^{m}\right) / P\left(h_{k}^{f}\right) \sum_{i, j=e, b, n} P(i) P(j) y^{D}\left(h_{k}^{f}, h_{l}^{m} i, j\right), \quad i, j=e, b, n, \\
& E\left(y^{d}\left(h_{l}^{m}\right)\right)=\sum_{k} P\left(h_{k}^{f}, h_{l}^{m}\right) / P\left(h_{l}^{m}\right) \sum_{i, j=e, b, n} P(i) P(j) y^{D}\left(h_{k}^{f}, h_{l}^{m} i, j\right), \quad i, j=e, b, n,
\end{aligned}
$$

where e.g. $P\left(h_{k}^{f}, h_{l}^{m}\right) / P\left(h_{k}^{f}\right)$ denotes the probability that the husband supplies $h_{l}^{m}$ hours of work, conditional on $h_{k}^{f}$ hours of work supplied by his wife.

\section{A.5 Social Assistance in Germany - a brief overview}

In Germany, SA becomes relevant only if none of the other transfer systems (e.g. unemployment benefits, unemployment assistance) provide sufficient income support. 
According to SA legislation, persons who are able to work are obliged to make any effort to support themselves. In particular, eligibility for SA payments requires that income from other sources fall short of some specified basic minimum income level. As a consequence, persons who receive transfer payments from other sources may also be eligible for SA, if transfers from other sources are smaller than the specified minimum income level. However, while SA recipients may keep a small amount of earned labour incomes, transfer payments from other sources are fully deducted from SA payments.

The basic minimum income level is household-specific and depends on household size and composition. This minimum income is referred to as the "SA minimum income". More specifically, the SA minimum income specified to cover the so-called "socio-cultural" existence minimum consists of a basic rate ("Regelsatz") for each household member and a supplement covering housing and heating costs. Moreover, one-off payments for special needs may be added. The basic rate for each household member is referred to as the "basic SA rate". For the head of the household, for example, this rate currently amounts to about 300€ per month. 